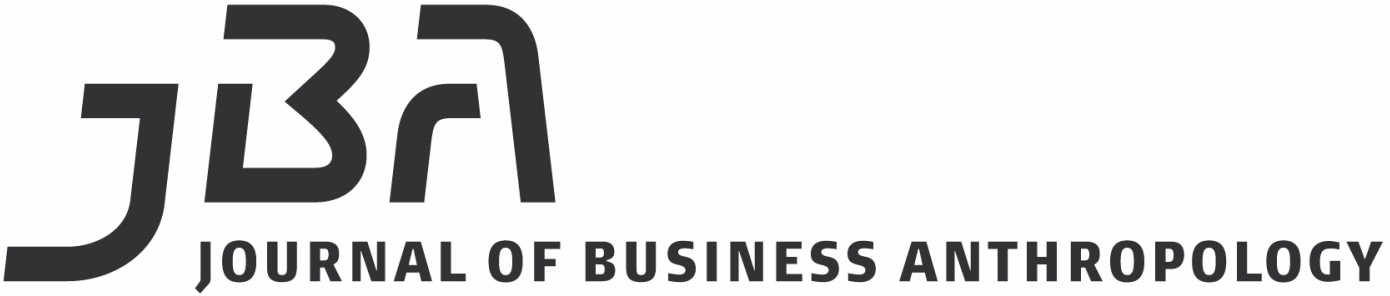

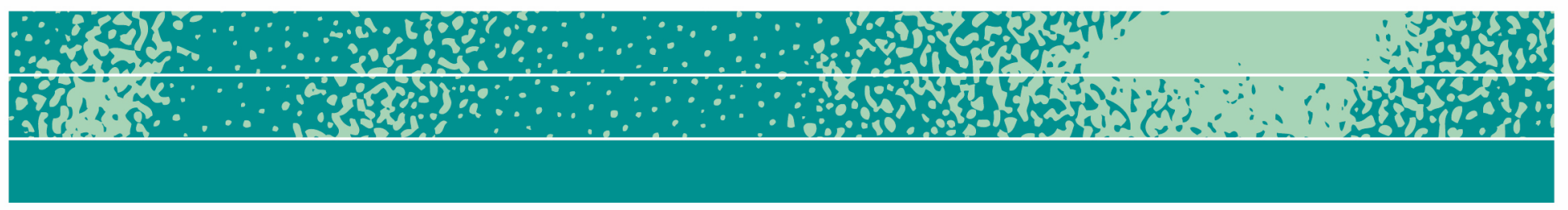

\section{Women's Softball and the Collaborative Spirit of Magic}

\author{
Timothy de Waal Malefyt and Peter Johnson
}

\begin{abstract}
All major US sports are high in superstitions because motivation to win is high and the game outcome is uncertain; athletes purportedly engage in superstitious behavior to reduce anxiety, build individual confidence and cope with uncertainty. Sports is also a male domain, where men traditionally display individual, masculine achievement. We observe magic rituals practiced in a women's college softball team not as a means to overcome anxiety or display individual prowess, but as a way to blend creative individuality into the unity of the social whole, which manifests as a social narrative of the team. We analyze individual and team magic in two forms -institutionalized magic and individual superstitions - which build idiosyncratic behavior into a collective team dynamic. As such, this essay shows how women use magical power collaboratively. Women on a college softball team partake in practical work and magic, such that participating in magic through empathy and sensing one another creates team identity, allowing the reimagination of forms and outcomes.
\end{abstract}

Page 1 of 23

JBA 9(2): 331-353 Fall 2020

(C) The Author(s) 2020 ISSN 2245-4217

DOI

$10.22439 /$ jba.v9i2.61

27

\section{Key words}

magic, superstitions, women's team sports, collaboration 
Magic exists throughout history in many societies and its practice and belief among people support social, organizational and gendered features that are relevant today. Magic is not only alive and well in contemporary societies practiced under conditions of capitalism (Moeran and Malefyt 2018), but also thrives as a necessary component in the organization of sports. All major US sports are high in rituals and superstitions because motivation to win is high and the game outcome is uncertain; athletes ostensibly engage in superstitious behavior to reduce anxiety, build confidence and cope with uncertainty (Gmelch 1985; Womack 1992; Vyse 1997; Schippers and Van Lange 2006). Magic offers a practical attempt to alter results (Vyse 1997).

We look at magic practiced in a women's college softball team, however, not as a means to overcome anxiety, but as a way to blend creative individuality into the unity of the social whole, which manifests as a social narrative of the team. We see this activity as a particular way for women to express and achieve magical power collaboratively. In this ethnographic study of a women's college sports team, we investigate how female team members encourage the joining of two forms of magic institutional and everyday magic - such that personal superstitions of individuals become social and collective magic for the team. We seek to explore the ways in which idiosyncratic superstitions generated by individual women team members appear to blend into and work their "magical" effect on a larger social whole of the team. While many sports events, including most male team sports, encourage a collective spirit, perhaps best exemplified by the spirit of $w a$ - the group harmony of besuboru that Robert Whiting (1989) studied in Japanese baseball — we likewise find the celebration of a collective spirit in this version of American college women's softball. Beyond this, the women's collective spirit we investigate also appears to be the means to create a powerful social narrative for the team. The team spirit of women's college softball not only supports a "collective effervescence" that Durkheim (1965) identified in religion, but the joining of individual identifiers helps craft and shape a social narrative that generates a larger mythology of the team, which further sustains the team's dynamic. Through an emphasis on empathy, affective relations and associations, the women's softball team heightens team member's awareness to make meaningful associations between individual acts and larger collective sentiments. In this way, as Susan Greenwood (2009) posits, magic becomes a mode of participation and mythmaking that is based on a mystical mentality and social behavior. Using magic's effects collaboratively rather than individually, women on the softball team participate in magic through empathy and sensing one another to create team identity, allowing the reimagination of forms and outcomes.

Baseball as a business enterprise in America generates more statistics and official/unofficial records than any other sport, and sports 
are big revenue streams for colleges and universities (Cahn 2015). College athletics generates a significant amount of revenue measured at $\$ 18.8$ billion in 2019 generated by over 1,100 schools (Besser 2016). Moreover, participation by women in collegiate athletics is widespread. Each year 430,000 student athletes participate in NCAA-sanctioned sports and 44\% of them are women (NCAA 2020). The vast majority of collegiate student athletes and virtually all women play for non-monetary reasons that include team and school recognition and personal accomplishment. Thus, although women athletes have little personal financial incentive, they invest significant time and energy into sports competition as individuals and as teams. Their efforts go beyond monetary into areas that relate to education, pride, and more abstract goals. (Simon 2014). Therefore, undertaking an understanding of a sports enterprise is valuable in showing how business anthropologists make sense of social realities.

We first discuss magic in two modalities - as a social institution practiced generally by a male specialist for specific events, and magic practiced daily by men and women as a means to mitigate stress or feelings of helplessness in uncertain occasions. We then discuss the world of sports, which historically has been the province of men where the "qualities of aggression, competitiveness, strength, speed, power and teamwork have been associated with masculinity" (Cahn 2015: 3). We then discuss our ethnographic findings of women's college softball, and how individual superstitions add up to a collective spirit that narrates the team. We conclude along with Greenwood (2009) that shared magic among women softball players is indeed a gendered form of participation that moves from individual orientation to a collective sensibility that is expressed through mythologies and stories that empower the team.

\section{Institutionalized Magic}

Anthropologist E.E. Evans-Prichard believed magic was closely aligned with social institutions. In fact, he felt magic could only be "intelligible when it is viewed not only in relation to empirical activities, but also in relation to other beliefs, as part of a system of thought... the system itself making sense only in relation to other institutional systems, as part of a wider set of relations" (1965:112). Magic that is institutionalized is typically performed by a specialist- the magician, sorcerer, shaman, diviner, or witchdoctor - to benefit an individual or community, such as cure a sick person, ward off illness, predict a bountiful crop, bring success in war, or perform some other social function. Magicians are experts that possess certain qualities because of their dexterity and outstanding knowledge that lay persons do not. Whether a sorcerer, shaman or today, a successful inventor, fashion designer or financial trader, barrister or business leader, "it is their profession which sets them apart from the common run of mortals and it is this separateness which endows them 
with magical power" (Mauss 1972:29). Because they "prevail over uncertainty," (Malinowski 1954) they are widely recognized by society as able to accomplish things beyond the power of normal human beings. A magician becomes venerated on the grounds of his community, since it is a public opinion that "makes the magician and creates the power he wields" (Mauss 1972:43). Yet, in almost all of these cases and across most societies, the esteemed individual is male.

The widespread institutional practice of magic indeed shows a strong gender bias. Magic is typically a male domain of power and prestige for an individual in society. Generally, men become magicians through social rank and tradition, a role that is bestowed on them with prestige and honor in many societies that is passed down or granted socially. As Mauss explains, men do not elect to be a magician, they must be chosen (1972). In some cultures, women are also considered to have magical powers to bewitch as Evans-Pritchard (1976) showed among the Azande. However, Azande witch practitioners represent not the highranking elite but commoner classes, where witchcraft is carried out for nefarious intents. Among the Azande, witchcraft is a biological function and a corporal part of the body that is genetically passed on, not a social position granted by society. In fact, the higher-order witchdoctors in Azande culture that counter the bad spells of witches, are "very seldom" women, since "most magic is a male prerogative, associated with male activities" (Evans-Pritchard 1976:184). Likewise, in other cultures women who become powerful through magic are more often considered evil, where they gain power, not through social affirmation of the community but by corporeal possession. Their bodies become vessels or instruments of evil, and typically they act alone, as social outcasts (Mauss 1972). The point here is that institutionalized magic from male magicians is celebrated as a social good, while personal female magic is mostly considered negative and socially not sanctioned. This social construction of power and gender association in magic, however, is destabilized and inverted in our work, as we show that the magic of women's individual superstitions contributes to the overall social good of the collective team spirit in women's college softball.

\section{Everyday Magic}

Magic is also practiced outside of institutions in everyday occasions by ordinary people. Practiced on a daily basis by both men and women, magic can provide a sense of control over life's circumstances where its lacking, such as performing well under competitive or stressful conditions, as in school or in sports, or during times of crisis with indefinite outcomes (Vyse 2013). Stuart Vyse, a former Connecticut College professor, conducted informal campus surveys where he discovered that 62 per cent of students have their lucky pens, or wear 
lucky jewelry or clothing to exams; 54 per cent percent attempt to sit in the same seat for tests; and 38 per cent listened to their favorite pre-exam song - all various behaviors enlisted to influence luck (Vyse 2013). In another example, when business professor Lauren Block of NYC Baruch College was an undergraduate, she wore a lucky pair of Nike sneakers to exams. She performed well in them, so her roommate asked to borrow them to wear to tests and also scored well. Convinced their shared academic success was due to a "magical transfer of intelligence through sneakers," she and another co-author later published an article, claiming "a ritual that lasted for the next 2 years was born" (Kramer and Block 2014:215). Indeed, men and women rely on magical thinking and practices in the forms of superstitions, wishful thinking and taboo avoidance, which are often accompanied by charms, amulets or acts of faith to guide them through uncertainty (St. James, Handleman and Taylor 2011; Vyse 2013). David Graeber (2012) reminds us that terms such as "fate" and "luck" are, in fact, ways of revealing ambiguities and dealing with conflicts of temporal existence that all humans face in one form or another.

Malinowski (1954) affirms that magical beliefs and their rituals, in fact, support practical knowledge, or at least enhance or complement practical knowledge as a way to secure success. He found that, while Trobrianders were skilled gardeners who clearly demonstrated great knowledge of plants, soil types and garden care, they also performed magical ceremonies over their gardens to ensure success. Belief in luck, therefore, is not mere wishful thinking, but has tangible effects: it can improve one's performance in a specific skilled activity (Vyse 2013). Magical thinking may be viewed as a coping mechanism for dealing with everyday anxieties, which "works to restore the experience of interconnectedness in situations where this experience has been broken" (St. James, Handleman and Taylor 2011:633).

This phenomenon of magical thinking for individuals has been observed to be widespread in sports. George Gmelch, himself once a professional baseball player, has described the various rituals a pitcher goes through (touching the letters of his uniform; straightening his cap after every pitch; washing his hands at the end of every inning in which he has given up a run). A batter will go through very much the same sort of mannerisms (like tapping the home plate three times before batting). Both pitcher and batter practice daily routines to overcome the fact that pitching and batting are ruled by luck and uncertainty (Gmelch 1985). In fact, numerous male baseball players are famous for their quirky superstitions. Mark Teixeira who played ball for the Texas Rangers, Atlanta Braves, and New York Yankees famously wore two different colored socks during games. New York Mets pitcher R.A. Dickey named each of his bats, such as Orchrist the Goblin Cleaver, or Hrunting. Hall of Fame player Wade Boggs ate the exact same meal before each game (Knapel 2012). While we also evidenced rituals and superstitions in 
practice among women softball players before games, during games and in team practices, what began as individual behavior joined the collective whole without overemphasizing one woman's superstition over another. Rather, women crafted a collaborative narrative of their sports team that set them apart from other teams, and which gave them a sense of collective purpose.

\section{The Male Domain of Sports}

Sports is traditionally a male domain of individual power, authority, and for expressing skill and competence. Historically, it is associated as a male rite of passage, a form of bonding and way to show prowess. Since athletics have long been the province of men, "qualities of aggression, competitiveness, strength, speed, power and teamwork have been associated with masculinity" and create a challenge for women athletes who wish to compete (Cahn 2015:3). In fact, Cahn (2015) writes, there are social issues when women assume these qualities, revealing a tension in women's sports between women appearing too masculine and being feminine. While baseball in particular comes off as "an essentially American experience," reflective of American ideology and worshiped "like a church" (Will 2010), Ferranti claims it also embodies a sacred nostalgia for a "pure and perfect experience of individual, masculine achievement;" one that is normalized as natural expression of the "patriarchal order" (Ferranti 1994:238). Cahn further argues that sports more than any other social or public arena, generates a tension in American culture for the blurred "boundary between male and female spheres of activity...” (2015:3).

The film, A League of Their Own (1992) explores this tension as it popularized public awareness that women played baseball professionally in the All American Girls Professional Baseball League, from 1943-1954. It was initiated during the war years to drive public attendance at home and boost morale with so many young men gone and enlisted overseas. Still, the public ambivalence of female professional baseball players was evident in that the 'girls' were required to attend charm school, dress fashionably and move gracefully while competing as professional athletes.

Ferrante further argues that a taboo still exists against women as polluting objects in baseball, which derives from women's mundane, corporal and sexual temptress associations that interfere with male success in baseball competition. "The major source of purity in the cultural symbol of baseball is the taboo against women's participation and a positioning of women as the sexual other" (Ferrante 1994:254). In the cultural lexicon of baseball and sex, many figures of speech still suggest sexual innuendos: "getting to first base," "a home run" or "striking out" referencing sexual success or failure (ibid:248). 
In mediating this cultural tension, Ferrante suggests that softball rather than baseball may be more acceptable for women to play, with its larger padded ball, pitched underhand at slower speeds, and hit shorter distances than men's baseball. This apparently 'softens' the public display of women's power (ibid:244).

Today, despite Title IX passed in 1972 to end discrimination on the basis of sex, and even though women have closed the gap in college sports when in 1970 women only received $2 \%$ of athletic budget, women still end up short. While women make up 51\% of Division I college students and secure $45 \%$ of athletic opportunities, they receive only $42 \%$ of scholarship dollars and $28 \%$ of total monies spent on athletics (Cahn 2015: 287). Moreover, even with the expansion of women's sports in college, women hold only 1 in 5 collegiate head coaching positions, coaching fewer than half of women's collegiate teams and only 2 or $3 \%$ of men's teams. (ibid: 288).

Women's participation in sports is now widespread but reflects a long historical struggle with gaining acceptance, since it relates to issues of power and authority in society. Women historically gained public acceptance to sports via their implied social role: physical activity promoted health and vitality, so they could bear children and be better mothers, or through notions of community - to better to serve others (Cahn 2015). In fact, recent studies show that women's power and authority is seen as less threatening to male power and even becomes admired if and when that power is considered communal (Manne 2020). This is especially so when women enter traditional domains of male power, like corporate work and sports. The power women show must benefit the caring and serving of others; then it is considered nonthreatening to men (Manne 2020). Likewise, in sports, women's team sports historically were a way for women to gain acceptance and show competitiveness and individual skills only when it was part of a collective team effort. Power for women is not as accepted for individual prowess and achievement, as with men, but when it serves the greater communal good.

When considering arguments that support women as leaders in business and government, evidence shows that women are better collaborators than men, and can create consensus better than men; and countries with women leaders have generally fared much better during the pandemic than countries with male leaders (Bostock 2020). Is collaborative magic observed in women's softball, then, a way for women to transform individual expressions of identity and power into a creative pool that serves the communal good of the team?

Perhaps magical rites in sports observed in the Fordham women's softball team do reveal a collaborative way for women to express and achieve public acceptance of magical power - as individuals with 
superstitions that support a collective team with rites and rituals. Women's individual idiosyncratic superstitions, then, are best acknowledged when they add to the collective whole. Perhaps women in team sports also celebrate creative individuality collaboratively in ways that enhance a sense of unity that benefits others.

\section{Methodology}

\section{Ethnographic interviews and Observations}

Ethnographic interviews were conducted in the fall school semester of 2018 with 8 college age women, 18-21 years old, and 2 coaches at Fordham University in New York City. The women were from educated backgrounds, in the process of completing their bachelor's degree, single, Caucasian and from middle class to more affluent households.

Interviews with the 10 research participants were conducted in the context of the softball games and practice. Each interview lasted approximately 2 hours. An interview guide was structured with openended questions to learn about ritual practices, concepts of sports, individual superstitions, team rituals, and softball traditions in particular. All interviews were recorded and later transcribed for accuracy.

Players and coaches were observed in context under competitive conditions of scheduled games. Observations of both the players and coaches in the game, and before and after rituals were also added to the analysis and interviewing. Also, players were visited during warm-ups and team practices and pictures were taken of many of the team and individual players.

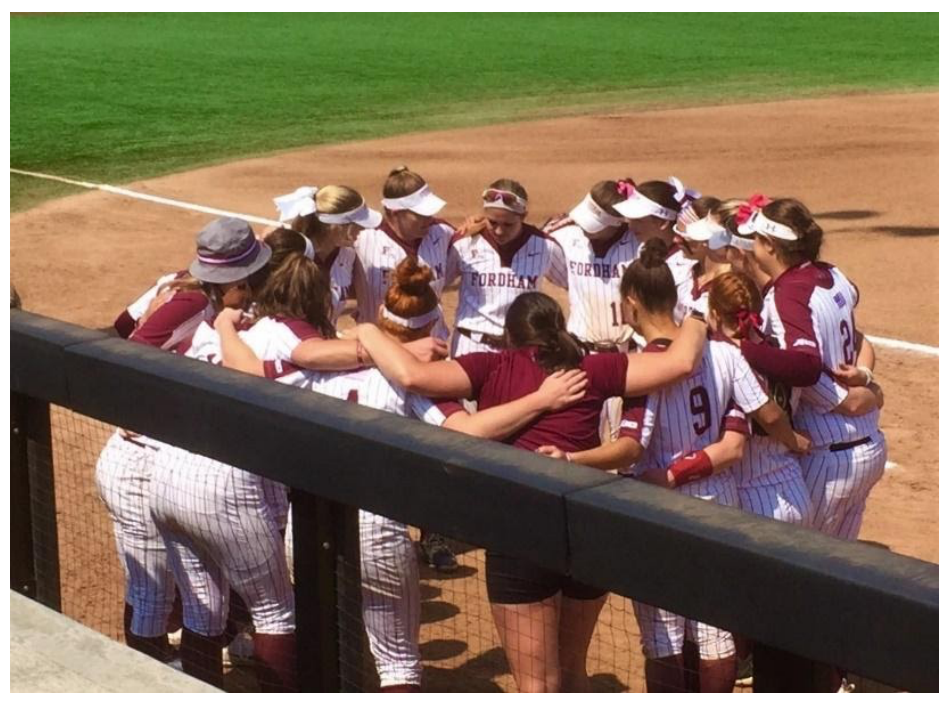

Players always gather before the start of each game for singing, chanting and mutual support. Note the variety of head wear and personal accessories.

\section{Cultural analysis}


Ethnography is "an interpretive act that occurs with the writing of texts," such that careful observation as a participant is a way of replicating the social reality of others (Van Maanen, 2011:4). After listening and observing players and coaches interacting, we analyzed the interview data in terms of emic categories rooted in anthropological theories of magic. Our analysis is focused on the stories that participants tell of themselves in relation to sports, other players, the team and personal experiences. We identified cultural patterns and themes as we sought to understand how the process of behaviors, motivation and socialization evolved. Analyzing discourses involved understanding the cultural logic of players, and "the rationale behind how they interact with others" (Hasbrouck 2018:29). We identified patterns underlying the players' discourses and the contradictions and conflicts they created. During participant observation of research participants, the researchers observed participant actions and reactions to the sports experience as it unfolded. By combining the methods of interviewing, photo collection and participant observation, we obtained a multifaceted view of behavior that yielded rich material and insight from cultural analysis.

\section{Findings: The Organization of Magic and Softball}

Magic is institutionalized for women softball players in ways that enhance and complement the organization and structure of softball. The work of learning practical knowledge and skills in softball is kept separate from magical practices; and magical practices themselves are oriented around clear rules for their appropriate place, time and circumstance. But unlike instances of other institutional communities of magic where males are singled out and celebrated for magical behavior, women softball players coalesce their particular superstitions for the overall benefit of the team.

In comparing the two systems, softball traditions and magical practices, players first develop softball skills through practice and work, later learn superstitions after joining the softball team. While traditional warmups and practice orient players to the game, superstitions are learned as separate and distinct part of their routines to complement practice. This division and separation of practice - practical work from magic - is comparable to sports organization of roles and is noted by anthropologists in studies of native systems of magic.

In softball as in baseball, the fielding team's positions are organized around a pitcher, catcher, first baseman, second baseman, shortstop, third baseman, and three outfielders at left field, center field and right field. The team functions as an assemblage of distinct roles that work together in harmony as a collective to perform their best. The importance of overall ball player organization, and players knowing their distinct positions is critical to team functioning and general team success (Will 2010). Each player responsible for her position, but also must work 
together to ensure team success. A large part of the role of coaching is integrating players effectively so that their individual contributions are greater than the sum total (Will 2010). Teams are thus built on organizing practices that coordinate individuals within the overall team.

Anthropologists likewise observed that institutional magic is surrounded by strict organizing principles. Similar to the actions of our ball players, magical rites have roles and are kept distinct even as they complement each other, and never replace hard work. Bronislaw Malinowski who studied the Trobriand Islanders in the South Pacific explained that the native knows when cultivating a garden that good results are guided by mental and physical effort: If fences are broken down and seed washed away, the native "will have recourse not to magic, but work, guided by knowledge and reason" (1954:28). But experience also teaches the native that in spite of forethought and effort, there are agencies and forces at work beyond his control, such as weather, noxious insects, and invasive animals for which he employs magic. Marcel Mauss (1972) also viewed magic as a system of social facts in native societies. Mauss called magical rites a "partner" to the efforts of native work: "Magic, in general, aids and abets techniques such as fishing, hunting and farming" (1972:24). Magic does not replace the work of learning skills, techniques and their results, since "everyone knows that the results are achieved directly through the coordination of action, tool and physical agent" (1972:25). Still, "(magical) rites are eminently effective, they are creative, they do things" (1972:23-24). Both anthropologists concur that magic complements, but does not replace the application of skills, techniques and hard work needed for regular social duties and responsibilities.

Similarly, we found in our study that players responsibility is first to apply the traditional work of practice, where they learn and develop skills and techniques as ball players. Superstitions do not replace or substitute the players' own hard work and diligence in practice, but importantly complement and enhance a person's acquired skill. We observed this among ball players - when joining the team, they first put in hours of practice, and later adapt superstitions along the way. Senior members of the team pass on knowledge and traditions to new members of the team.

Beth describes joining the softball team: "Well, starting off from practice we had a set amount of things we had to do. The older girls told us how we had to warm up... who you throw with... who you get comfortable with. If you are an infielder or an outfielder there's a certain amount of throws you have to do. Basically, the coach is really establishing how practice is gonna go every day!"

Patti also discusses warm up routines as "given and learned" from the coaches and senior players. Much of what we observed players do for 
warmup is a set practice. Patti explains: "They tell us what they want us to do before games. Our strength and conditioning coach sets up stretching and what specific stretches we must do before a game."

Beth also affirms, "If you're an infielder or an outfielder there's a certain amount of throws you have to do. Basically, the coach establishes how the practice is going to go every day and it's basically the similar things we do to get started for practice."

Margaret also describes order, stating: "There's a certain order of stations that I go through and then I do a number of certain throws with one of my teammates. I always have the same throwing partner so then I do a bunch of different throws, like the long toss, and then I work on some side arm throws with her."

Coach Grove on game day affirms the importance of order for the players, "I always prepare my lineup the same way; I would never change that... Pregame habits are fun in the context of softball; they help 'settle us in."”

Along these lines, Sherri states, "[When batting] I get nervous and shaky and I think that that affects my performance; but in turn I don't think so because I know how to do everything. We've practiced ample amounts of times. I know how to hit, I know how to field the ball but it's just something about doing my pregame ritual doing everything the same way every time just makes you feel good, yeah, yeah!"

Teammate Lisa affirms: "Obviously preparation comes in practice and getting to the field and warm-ups and everything like that. But [ritual] is kind of like the solidifying factor when you know it's game time. That's good."

And Beth notes: "I feel like we're a lot like other sports: it's about consistency and doing the same routines over and over again; having the simple things done right. So I feel like that rituals play into just overall performance."

At first Patti describes practice as somewhat formal, distant, ununified and built on 'norms': "In the beginning practice, it's separate... the outfielders have their own huddle and the infielders have their own and you never really see an infielder in the outfield huddle and vice versa so it's not necessarily 'oh you can't join us' but it's the norm that the infielders stay together they warm up together."

But Patti then discusses how the formality of team structure over time melds into a sense of familiarity and knowing other players personally, especially through rituals of handshakes: "A lot of it is having a set lineup; we all know what position we're gonna play, where we're batting in the order and that has a lot to do with where we're standing. In the beginning [of the season] we develop handshakes based on each other's personalities, so we've been practicing every day with each other 
since August, so you learn about each other and then that's a way of bonding."

These comments by players affirm that softball practice at first begins as a formalized structure of work. But later in the season, as players get to know each other, their shared rituals create a bonding experience with the team.

\section{Practices of Magic and Softball are Highly Prescribed}

Part of the organizing work of magic is knowing when to apply magic and for which occasion. Institutionalized magic is highly organized in a community where there are clear divisions of labor, roles and an appropriateness in knowing when to apply either practical work or magic for a situation. Malinowski affirms this, stating "Every magical ceremony has its distinctive name, its appropriate time and its place in the scheme of work, and it stands out of the ordinary course of activities completely... the two roles never overlap or interfere: they are always clear, and any native will inform you without hesitation whether the man acts as magician or as leader in garden work" (1954:29). Malinowski continues, "while fishing on the inner lagoon is done easily with skill, knowledge and practice...in the open-sea fishing, full of danger and uncertainty, there is extensive magical ritual to secure safety and good results (1954:31). For efforts of gardening or open sea fishing, magical rituals or applied work depend on the right conditions or circumstances for application, or they fail to work. Mauss similarly affirms that magic is not performed just anywhere or anytime, but organized in "specially qualified places" (1972:57). In fact, magical rituals are organized for the community such that, "The time and place of the ritual are strictly prescribed. Some ceremonies may take place only at night or special hours of the night. Others at special times of the day... other times of the month, the year or lunar dates coincide with precise timing of rites" (ibid). Both anthropologists concur that magic's application adheres to proper time, place and circumstances to validate its effect in the community.

We likewise heard softball players discuss the importance of ritual order for magic to work effectively for the team. If out of place, the magic would fail. Sherri notes, "When we come up to the pitcher's mound before a game, we all stand in the same place together. If we stood in different places, the whole mojo just gets thrown off."

Similarly, Margaret says, "Before every game we have a Hail Mary thing that we do with the coach. We've learned that it's in every game that we do. Also, when we play on our home field, I always go to the middle of the field first, so we don't lose on our home field. We like say, 'count to three' for defense, and then on three, we say; 'one, two, three.' That's always been two main rituals we do before a game in that order ever since I've been here." 
Beth discusses following a magical protocol in helping the team get hits: "We have this thing in the dugout that we did with a 'magic bat.' All the girls would pass it down before to try to start a hitting rally. It ends up working and someone ends up getting a hit; it's really weird but it happens every time we'll pass around the bat and then we'll start hitting. We each have to touch it before the girls go up to bat for it to work."

Applying the knowledge of order and appropriateness of when to use magical rites and for the correct circumstance is thus part of team unity. Magical superstitions of individual players join a collective effort for the entire team in assuring a degree of success in softball.

\section{Individual Superstitions Join the Collective Group}

We also observed the way players learn and acquire their own private superstitions after they join the team. Learning superstitions is not something formalized but is encouraged as something personal and creative, and helps individual players adapt to the team. Developing a superstition allows the individual to better connect to the group, as it also reflects the creative 'subjunctive mode' of magical possibilities that Turner (1969) referenced.

Skylar discusses the personal development of her own superstitious ritual: "My freshman year I was figuring everything out, trying to make my way into the lineup, so I had to figure out what would work for me; I think once I found my little routine that was when I started doing well because I felt good about my routine so I felt good going up to bat."

Sherri added her views, "most of the girls each make up our own handshakes with each other so we do that on our own time but then the upperclassmen would teach us [to] line up this way you go through the line and you do this you do that...but we learn on our own how to do these different handshakes. This is how we learned our superstitions.'

Lisa also says, "the handshakes have to be made on the fly; it can't be, 'Oh I sat there, and I thought this should be our handshake. It has to be made in the game or based on something that happened. Yeah, improv because that's what makes it unique."

Patti also affirms: "We each have our own different handshake with one another, and that gets us excited and ready to play."

Even for the coach, her personal superstitions blend into the collective team effort. For instance, over five years ago coach Grove developed a creative habit of bringing a complete bag of clothes to each game that contains what she calls: "my hitting jacket, score-a-run jacket, winning pants, strikeout wristband" and more. This turned into a narrative of wearing a "themed" cloth item to clearly signal to other team 
members a desired material outcome that the coach playfully intended. This action also indicates a level of mimesis or imitative magic at work that implies team community building and connectivity. Michael Taussig (1993) discusses how imitative magic implies both copy and substantial connection. Copy and contagious contact are steps in the same process and are harnessed together in a two layered notion of mimesis. Imitative magic copies another form, merging one to become something identical in one process of sensing, seeing something or having sensual contact with it. The created similarity of the two things then restores a sense of unity lost through distance or separation. In this way the coach copies a desired result and connects with the players, affirming the role of mimesis in bringing about unity.

A team player, Claire, affirms her coach's efforts, stating: "Our Coach is very superstitious. She is not on the field, so she doesn't have any control over the play. The players are superstitious too, but we can kind of control the outcome of the game; but our coach can't control anything so what can she do? 'Oh, she's gonna be superstitious! And we need all the help and everything to win so there's an association between the [coach's] superstition and our team's performance."

Thus, imitative actions create a further sense of emotional connection, uniting the coach's feelings and personal magical efforts with an emphasis on team unity, performance and outcome. Learning superstitions add to a collective whole of the larger team effort. Everyone on the team seeks ways in which their individual superstition may fit or add to the group collective. For the softball players, collaborative magic rituals are clearly ordered and practiced with attention to circumstantial details and help direct individual behavior. The team structure helps shape individuals, as personal rituals contribute to the entire spirit of the team.

\section{Creating a Team Vibe}

Other scholars have claimed that superstitions and rituals among teams ascribe a functional sense of membership to groups. Vyse (1997) claims superstitions in sports teams, gambling and theater groups lead to membership because they involve acts of socialization of conformity or compliance by the group. He claims to the extent people want to be accepted, they are willing to adapt magical practices of the group; and athletes acquire the language and skills of the game as well as particular habits of the team to fit in (1997:162-4). Socially shared superstitions become part of group culture and individual members adopt them as part of socialization to the group. Exposure to group practices includes social learning, direct instruction and reinforcement by others in the group, as means to conform to peer-pressure and to demonstrate commitment towards the team (Vyse 1997:97). Schippers and Van Lange (2006) also 
claim new members will likely acquire superstitious activities as it helps them to contribute to team belonging.

Nevertheless, we posit that learning individual superstitions and team rituals are not necessarily obligatory or done to conform to the group. Rather, they comprise a creative dimension that inspires the narrative 'vibe' of the team. For new members of the softball team, rituals allow members to be part of the community, especially since they are taught and passed down by senior members of the team. We observed this in the context of pre-game warmups, where the importance of preparation rites is crucial to the feeling of fostering a sense of togetherness before a game.

Margaret, a senior team member, explains about teaching the rituals to the team and how this builds towards a collective identity: "We actually do go over (pre-game routines) a bit in the fall practices, leading up to games. It's like we say, you're a third base and you have to throw the ball to the first baseman, and then first baseman has to throw to catcher, in that order. And with the handshakes, you work with this sort of person outside of practice. You just sort of find that rhythm once you get into it."

Lisa also discusses the collective team practice of the pregame line up and special handshake that members all share with each other. "In the fall, you get a sense of unity, and feel like an integral part of the team when we all stand in the circle around the pitcher's mound making handshakes with people. You get a sense of belonging, being part of something. The handshake is made on the fly. It's just a 'vibe.' We need a handshake because it brings us good luck."

She continues, "Each handshake goes with our relationship with each other. I don't have a handshake with everyone because I'm not as close with some people. But the handshake I do have with others are like little components of our relationship with friends I do have personally and on the field."

Lisa also discusses improvisation on handshakes as a way for each player to develop her own sense of style. This individual act opens the team to good fortune, even as it adds to a sense of preparation: "The handshake we do at the beginning brings good luck. It gives you a sense of readiness to play, being prepared; it's the cherry on top, being prepared. Obviously, we have preparation from the practice and getting to the field and warm-ups, but (the handshake ritual) is the solidifying factor that it is game time." Patty affirms, "Making handshakes with others makes you feel like you fit in more... which is important when you're new to the team."

Beth adds to this, "When we saw our first game, we saw that a lot of the older girls were having handshakes and they came up to us and said we have to have a handshake before the game, too. I feel it gets you motivated, and it shows that we got each other's back and we're there for 
each other and I think that helps going into the game as well." She also says, "you do get that sense of unity when you're all standing in the circle hearing the lineup and then you're going down the line and you're doing handshakes with people so you do get that sense of belonging and that you're a part of something."

Paige reenforces that the personalized handshakes begin spontaneously and then transfer into part of team preparation and mutuality. "The high-five is old and boring, so we've developed these handshakes; they may include chest-thumping or concentration playing...we each have a different handshake with one another and that gets us excited to play and ready to play. My roommate on the team and I came up with one where we always slap each other high-five, slap our thighs twice and then elbow right to left and then left to right and then 'booty bump' each other. That's a cool one that I have. Coaches or teammates don't force you to do anything which is nice but you don't wanna be the odd one out so making handshakes with others makes you feel like you fit in more."

We observed that food and beverage magic associations, that are cited in men's baseball (Gmelch 1985) also play a part in women softball. Caroline once pitched a one-hit shutout and now on every day she pitches she has the same green tea and sandwich breakfast at Starbucks. She does this for herself and to give the team assurance of her best performance. "I kept doing it and we won that year. We won the conference for the first time in 21 years. I've done it ever since including travel ball games. The girls help me find the nearest Starbucks,"

Unlike men's sports, we also observed that women softball players apply magical thinking to hairstyles, makeup and personal accessories and make note of stylistic changes with other players.

Caroline is highly aware of other player's individual appearances and how they change depending on the success of the collective team: "I don't change my batting ritual but if we are losing, I'll change the way I do my hair or I change the eye makeup I wear or I change my sports bra and spandex. Last season I stayed with [the same] hairstyle for every single game regardless how I did. Then this year we've had a more up-and-down season so I've done well in the pink bow I have or if I braided my hair to the side I kept doing that hairstyle until I had a bad game and then I would switch it."

Susan [the team captain] wears the same lipstick and the same pink bow every single game and last year she had same hair every single game but this year she switched her hair. I know Skyler, our other senior, wears the exact same sports bra every single game. Oh, and my catcher Kylie wears her hair in a braid like a straight down braid and the one game she didn't she did really bad so she hasn't changed." 
Players also seem to be aware of contagious magic that is spread with touch or personal contact. Chelsea says, "Whenever there is a twoand-two count [for our batter] we all have to touch each other's hands in the dugout and if we don't touch, our batter always does bad. Then if she gets to a two and two count, we touch with two fingers and then it gets to a full count and we just touch with one." This is an example of players using touch and hand symbols to create magic to transfer to a teammate.

In a ritual borrowed from professional baseball, all players now have a "walkout song" that is played through the stadium sound system when a player comes up to bat. A player selects a song she prefers and that is reflective of her personality, which also generates enthusiasm and cheers from her team in the dugout.

\section{Discussion: Fostering a Team Narrative}

We claim organized magic from individual players build towards the overall unity of the women's softball team. We note that skills practiced individually in ritual superstitions develop certain patterns when practiced repeatedly and frequently among members of a sports team. Sociologist Richard Sennett concurs, "there is a rhythm which governs the development of human skills" (Sennett 2012:200). Such pattern or rhythm of skill-development becomes ritualized when practiced again and again in the face of stress and uncertainly. In this way, rituals help individuals harmonize with each other so that they become more aware of their collective unity and individual efforts in overcoming uncertainty. We note the harmonizing of individual superstitions into team rituals has a likewise effect of creating a harmony, rhythm or team spirit.

Expressing fear and anxiety before a sports game may offer a perception into a problem. Using magic in uncertain times and under high risk situations may be an individualized strategy to reduce anxiety. The psychological effect of reducing anxiety is one way to diminish outside noise and stimulation, which causes the individual to step back (Sennett 2012:212). But we hold that women's team sports and ritual practices creates more of a positive collaborative endeavor. Magic is used joyfully and unashamedly publicly to deploy skills, which we observed in individual and team rituals, and which allows team members to become more aware, more sensitive, connected and more engaged to each other in the environment of the game. In other words, through ritual, the player is not just reducing anxiety nor conforming to a group standard, but reimagines her form and use of objects in a game (i.e., swinging a bat, fielding a ball, running the bases) as a way of altering a condition that needs attention. Superstitious rituals from individuals thus feed into the collective hard work, practice and team coordination to create a feeling of togetherness and a narrative of group unity. 
A personalized superstition does not serve the individual, as mentioned earlier about the male baseball celebrities each with his own quirky idiosyncratic behaviors. Rather, luck among the women softball players is shared. Sherri discusses how luck from an individual is intentionally shared with others on the team. "When one person starts doing well, that energy goes through everyone else. So, we're down, and one girl gets a hit, and you'll notice that everyone will start hitting. And if one girl is 'hot' and doing well, other girls will come up and rub her on the shoulder, saying 'gimme some hits.'

Beth discusses the collective effects of magic. She states, "I think (superstitions) can bring a sort of comfort especially in the game of softball where one hit can change the whole entire game. You have to be on your toes all the time. I think doing these sorts of rituals in the pregame relaxes people and okay, this is something we know so that whatever happens in the game, we know the game can get crazy. At least in our pregame we can rely on these sorts of rituals to center ourselves and get us focused for the game."

Lisa adds, "We also have a team ritual - we all take a deep breath together as a team, to become all in sync. Sometimes we even sing together. This helps control our emotions and control our actions together."

Supporting this point on the collective use of magic, Susan Greenwood writes that magic can be a powerful mode of participation that is based on emotion and affective relationships and associations (2009:29). Through a mystical mentality magic has an effect on social behavior. The concept of participation changes people's awareness to make associations and connections between things, situations and feelings. This is a key concept among women softball players on the Fordham team. Individual magic in an institutional setting is not practiced as a way for people to stand out and gain social recognition as Mauss, Malinowski and Evans-Pritchard found among men in their societies studied. Rather, for women players on a team, "Participation is an orientation to the world that can be expressed through mythologies and stories” (Greenwood 2009:31). The stories they tell “...are a language of participation - that take (them) deep into their imagination where different experiences are possible..." (ibid:32). Magical participation is thus transformative in relation to the everyday world, such that "feelings of personal connectedness and empathy are intense" (ibid:29). Moreover, these women do not simply follow and adhere to pre-existing team rituals when they join. Rather, their rituals come into being through "making" (Ingold 2013), as women craft them through collaboration, sensing one another, and empathizing individual superstitions into a larger whole. As such, women confirm a central identity and social construct that is supportive of stories and myths they share about the team and with one another. 
Perhaps this research informs an unexplored dynamic in magic: that personal magic and institutional magic are not so distinguishable. Team players idiosyncratic taboos, wishful thinking and felt superstitions owned and recognized by individuals become merged and incorporated into a greater whole, thus showing how personal magic transforms into an institutionalized collective form of magic. The coach as leader and individual team players form part of the group, the collective "we" that they are passionate about.

Ritual patterns carried out individually and as a team are then focused on the collective. While rituals in sports may reduce individual anxiety, they can also improve social relations, build team spirit and collaboration such that they help reimagine what the players and team can produce together successfully. Magic, in the words of the ball players, creates the team "mojo," "rhythm," or "vibe," as it aligns players to be "in sync." The magic of the team in sync also creates a sublime state of 'play,' which sociologist Johan Huizinga affirms in its qualities and aesthetics “...casts a spell over us; it is 'enchanting,' 'captivating.' It is invested with the noblest qualities we are capable of perceiving in things: rhythm and harmony" (Huizinga 1950:10).

The social experience of softball is thus re-imagined by the coordinated teamwork of women's ritual actions. Ritual's role for the women's softball team then is to relieve and resolve anxiety by turning people not inward, but outward in shared symbolic acts of collaboration. Our point is to emphasize magic in women's softball as a form of organized cooperation for reimagining the collective identity of the team itself, which comes from heightened awareness of self and others in organized acts, both practical and magical.

\section{Conclusion}

Malinowski (1954) might claim that this research evidences behaviors that reveal more of a religion, something shared and followed by all, rather than individual displays of power. Furthermore, male team spirit and the magical rites of men's sports teams are also prevalent elsewhere. The historical novel by Daniel Brown (2013) The Boys in the Boat, popularized the team of male rowers from the University of Washington who represented the US in the Olympics at Berlin in 1936 and certainly showed a strong team spirit and rituals for working together and winning conducted before matches. Our paper does not attempt to argue that a women's team sport supports a cult of believers and followers, like a religion, or that it has more spirit than male teams, since many team rituals create a collective sense of 'we.' But the collective spirit among the Fordham women's softball team shows a way that individualized and creative behavior becomes channeled into known and shared stories that 
build towards a team focus, which has implications for affinity building and coalition of resources.

According to third wave feminism discussed in the introduction of Malefyt and McCabe (2020), there isn't a universal explanation for women's domination by men, that such explanation is not based on biology but on culture. This study is not reverting to either biological determinism or cultural essentialism. Rather, the women's team sport in describing the Fordham softball team and the goals to which their magical rites are oriented, use magic as a means to construct and further sustain some sort of social narrative of identity.

Taking this further, Donna Haraway (1991) affirms, "There is nothing about being 'female' that naturally binds women. There is not even such a state as 'being' female, itself a highly complex category constructed in contested sexual scientific discourses and other social practices" She continues, contrary to second wave feminists, "searches for a new essential unity" among women remains unproductive. Rather, she forwards instead a growing recognition of another response "through coalition - affinity, not identity" (Haraway 1991:155). Her observation about women building a coalition and affinity applies to this study in which feminine identities are not an end in themselves, but become contingent in time and place to offer a new narrative - one in which individual creativity coalesces and builds an affinity in creating a powerful collective and collaborative voice in the spirit of a team sport.

\section{References}

Besser, Dillon J. 2016. "The Forgotten Party O'Bannon v. National Collegiate Athletic Association: How Non-Revenue Sports Operate in a Changing Intercollegiate Marketplace." Iowa Law Review 101:5, pp 2105-40.

Brown, Daniel 2013. The Boys in the boat: Nine Americans and Their Epic Quest for Gold at the 1936 Berlin Olympics. New York: Penguin.

Bostock, Bill 2020. Female-led countries handled the coronavirus pandemic 'systematically and significantly better' than those run by men, study says. Business Insider, Aug 19, 2020 https://www.businessinsider.com/coronavirus-women-leadershandled-pandemic-better-than-men-study-2020-8.

Cahn, Susan K. 2015. Coming on Strong: Gender and Sexuality in Women's Sports $2^{\text {nd }}$ ed. Urbana: University of Illinois Press.

Durkheim, Emile 1965. The Elementary forms of the Religious Life. New York: The Free Press. 
Evans-Pritchard, E. E. 1976 (1937). Witchcraft, Oracles and Magic among the Azande. Oxford: Clarendon Press. 1965. Theories of Primitive Religion. Oxford: Clarendon Press.

Ferrante, Karlene. 1994. "Baseball and the Social Construction of Gender." In Women, Media and Sports, P. Creedon ed. Thousand oaks, CA: sage, pp. 238-256. https://doi.org/10.4135/9781483326764.n9

Graeber, David 2012. "The sword, the sponge and the paradox of performativity: some observations on fate, luck, financial chicanery and the limits of human knowledge." Social Analysis 56 (1): 25-42. https://doi.org/10.3167/sa.2012.560103

Gmelch, George 1985. Baseball Magic. In Magic, Witchcraft, and Religion: An Anthropological Study of the Supernatural, Lehmann AC and Myers JL (eds)., 5th ed. Mountain View, CA: Mayfield Publishing company.

Greenwood, Susan 2009. The Anthropology of Magic Oxford: Berg.

Haraway, Donna 1991. Simians, Cyborg, and Women: The Reinvention of Nature. London: Free Association Books.

Hasbrouck, Jay 2018. Ethnographic Thinking: From Method to Mindset. New York: Routledge. https://doi.org/10.4324/9780203712290

Huizinga, Johan 1950. Homo Ludens: A study of the play-element in culture. Boston: Beacon.

Ingold, Tim 2013. Making: Anthropology, Archaeology, Art and Architecture. London: Routledge. https://doi.org/10.4324/9780203559055

Knapel, Robert 2012. "Baseball's 50 Weirdest superstitions," May 11, 2012 https://bleacherreport.com/articles/1179538-baseballs-50weirdest-all-time-superstitions.

Kramer, Thomas and Lauren Block, 2014. "Like Mike: ability contagion through touched objects increases confidence and improves performance." Organizational Behavior and Human Decision Process 124: 215-228. https://doi.org/10.1016/i.obhdp.2014.03.009

Malefyt, Timothy de Waal and Maryann McCabe 2020. "Introduction: Women, Consumption and Paradox." In Women, Consumption and Paradox. Malefyt and McCabe, eds., pp. 1-24. London and NY: Routledge. https://doi.org/10.4324/9781003028109-1

Malinowski, Bronislaw 1954 [1948]. Magic, Science and Religion and Other Essays. New York, NY: Anchor Books.

Manne, Kate 2020. “There's Nothing Radical about a Female Vice President." The New York Times, https://nyti.ms/3jLtakp. July 28, 2020. 
Mauss, Marcel 1972 [1902]. A General Theory of Magic. Robert Brain, trans. London: Routledge \& Kegan Paul.

Moeran, Brian and Timothy de Waal Malefyt eds. 2018. Magical Capitalism: Enchantment, Spells, and Occult Practices in Contemporary Economies, London: Palgrave Macmillan. https://doi.org/10.1007/978-3-319-74397-4

National Collegiate Athletic Association 2020. NCAA financial database retrieved from ncaa.org/about//resources research/NCAA - finances database.

Schippers, Michaela and Paul Van Lange 2006. "The Psychological Benefits of Superstitious Rituals in Top Sport: A Study Among Top Sportspersons." Journal of Applied Social Psychology 36 (10): 25322553. https://doi.org/10.1111/j.0021-9029.2006.00116.x

Sennett, Richard 2012. Together: The Rituals, Pleasures and Politics of Cooperation. New Haven, CT: Yale University Press.

Simon, L. 2014. "Why unionizing college sports is a bad call; change at the NCAA can be achieved without turning student-athletes into employees." Wall Street Journal. Apr 07.

St. James, Yannik, Jay Handelman, and Shirley Taylor 2011. "Magical Thinking and Consumer Coping." Journal of Consumer Research 38(4): 632-645. https://doi.org/10.1086/660163

Taussig, Michael 1993. Mimesis and Alterity. London: Routledge.

Turner, Victor 1969. The Ritual Process: Structure and Anti-structure. Chicago: Aldine.

Van Maanen, John 2011. Tales of the Field: On Writing Ethnography, second edition. Chicago: University of Chicago Press. https://doi.org/10.7208/chicago/9780226849638.001.0001

Vyse, Stuart 1997. Believing in Magic: The Psychology of Superstition. Oxford: Oxford University Press.

Whiting, Robert 2009. You Gotta Have Wa. Vintage books.

Will, George 2010. Men at Work: The Craft of Baseball. New York: HarperCollins.

Womack, Mari 1992. "Why athletes need a ritual: A study of magic among professional athletes." In Sport and Religion, Hoffman, S (ed.), pp. 191202. Champaign, IL: Human Kinetics. 
Peter Johnson is a Clinical Associate Professor of Marketing at Gabelli School of Business, Fordham University. Previously he was in private investing and an executive in digital marketing companies including US Interactive and Modem Media. His published research includes organizational improvisation and the antecedents of market orientation.

Timothy de Waal Malefyt is a Clinical Professor of Marketing at Gabelli School of Business, Fordham University. Previously, he held executive positions at BBDO and D'Arcy advertising agencies, where he applied cultural approaches to consumer research for developing brand strategies. He has co-edited and co-authored 5 books including his latest, Women, Consumption and Paradox. 